\title{
OPTIMIZATION OF CUTTING SPEED AND CLEARANCE ANGLE IN THE DISC CHIPPER
}

\author{
Mariusz Reczulski \\ Lodz University of Technology \\ Centre of Papermaking and Printing \\ Poland
}

(Received Februar 2020)

\begin{abstract}
The wood chipping system in a disc chipper Carthage-Norman was studied. The study showed many operational problems related to obtaining chips of different length in the process of wood chipping. Excessive amount of fines and pin fractions were produced in the chipper. The reason for this was the too high cutting speed of the logs and the wrong clearance angle in the chipper. The actual and optimal distribution of the cutting velocity occurring on the chipper knife was determined using the Matlab/Simulink model. In addition, optimal clearance angles in the chipper were determined using the model.
\end{abstract}

KEYWORDS: Wood chipping, cutting speed, clearance angle, chip formation, disc chipper.

\section{INTRODUCTION}

The chip size and chip quality has important implications on pulp properties, pulp production, and pulp quality, particularly in the kraft pulping. Therefore the industrial plants that have wood chipping process, strive to produce chips of homogenous size and shape (Hellström et al. 2009, Law et al. 2000, Abdallah et al. 2011). The oversize fractions and fines are not considered good for cooking. Oversize and undersized fractions can also cause mechanical problems in the case of the use of digesters of continuous operation. Observations and studies (Reczulski 2015, 2016) have shown that the cause of formation of too small chips is often associated with improperly carried out chipping process.

It should be noted that the formation of too small chips is often related with the construction of the chipper. In this case, the main parameters that affect the length of cut chips are knife height $(\mathrm{H})$, spout angle $(\varepsilon)$, wedge angle of knife $(\beta)$ and clearance angle $(\alpha)$. The impact of the above operational parameters related to the wood chipping process on the quality chips has been studied by many researchers (Hellström et al. 2008, 2009, Abdallah et al. 2011, Smith and Javid 1999, Twaddle 1997, Reczulski 2018, Hartler and Stade 1997, Röser et al. 2012 and Uhmeier 1995). 
The cutting speed is also an important parameter of the disc chipper for the production of high-quality chips. Studies have shown that an increase in cutting speed leads to a larger amount of small-sized chips (Hartler 1986, Twaddle et al. 1990, Edelman 1992). Studies carried out in one of the industrial mills (Hartler 1996) show that both fines and pin fractions increase twice when the cutting speed increases from 15 to $30 \mathrm{~m} \cdot \mathrm{s}^{-1}$. Increasing the cutting speed leads to the production of a higher percentage of both small chips and fines, since other variables remain constant (Hartler 1996, Hernandez and Boulanger 1997). Manufacturers of chips often increase cutting speed to achieve greater the efficiency of disc chippers. Such actions are inappropriate from the point of view of the quality of wood chips. However, studies on yellow pine and oak showed that the increase in knife speed from $22.6 \mathrm{~m} \cdot \mathrm{s}^{-1}$ to $33.9 \mathrm{~m} \cdot \mathrm{s}^{-1}$ at 30,35 and $38^{\circ}$ spout angle resulted in more pin chips Smith and Javid (1999). Studies have also shown that there was little effect of spout angle on the generation of pins. In addition, studies have shown that lower knife velocities produced higher levels of overthick chips. These results clearly show the relationship between the wood cutting speed and the increase in the generating of unacceptable chip fractions (generating pin chips and overthick chips).

The challenge for chipper handling is to find the optimal log cutting speed to achieve high machine performance with the largest acceptable wood chip fraction. This also applies to drum chippers Ebrahim and Ghazy (2016). Industrial disk chippers usually work at a cutting speed of $20-30 \mathrm{~m} \cdot \mathrm{s}^{-1}$. Achieving these speeds without deterioration chip quality is possible due to the appropriate chipper design. Modern chippers have a lower cutting speed however this does not significantly affect the machine's performance. This was achieved, i. e. through having the cut surface positioned closer to the disc center, a more streamlined outlet of the chips and use of more durable knives. A common occurrence in industrial mills is the operation of the chipper with the too high cutting speed causing a decrease in the amount of acceptable chips and an increase in the fine fraction. The differences in the amount of both fractions may slightly change depending on the type of cutting wood.

The analysis of the chip formation is quite complicated, because wood is an anisotropic, heterogeneous and hydroscopic material. In addition the distinct characteristics of juvenile and mature woods, have an influence on processing due to their different mechanical resistance properties in relation to cutting operations Goncalves and Neri (2005). In addition, the wood properties such as density (Petráš et al. 2019, Schönfelder et al. 2019, Szabolcs 2015), temperature (especially if the wood is frozen) Hernandez et al. (2014) and moisture content Güntekin (2016) also affect the wood chipping process (Papworth and Erickson 1966). The aim of this paper is to show the impact of wood cutting speed in a wood chipper on the quality of chips produced. Using the computer simulation, the clearance angles in the tested chipper were also optimized.

\section{MATERIAL AND METODS}

The study was performed at the mill with the system wood chipping and pneumatic conveying system for wood chips to the landfill. The wood chips were produced in the disc chipper Norman - Carthage. The chipper has a profiled disc with a variable clearance angle along the length of the knife, in the range of $3^{\circ} 25^{\prime}-1^{\circ} 40^{\prime}$. The minimum and maximum cutting radius in the chipper was 0.32 and $0.93 \mathrm{~m}$ respectively. The tested chipper had gravity feed configuration with a spout angle of $38^{\circ}$. The chipper was equipped with $15 \mathrm{knifes}$ on the disc having $2440 \mathrm{~mm}$ in diameter and a thickness of $152 \mathrm{~mm}$. The revolutions on the outlet shaft are $\mathrm{n}=370 \mathrm{~min}^{-1}$ and power of the motor is $630 \mathrm{~kW}$. The chipping machine productivity was $400 \mathrm{~m}^{3}$ chips per hour. 
Vol. 65 (6): 2020

The chipper has pneumatic discharge of chips to cyclone. Spruce wood from state forests with the average moisture content range of $46.5 \%$ was mainly chipped. The moisture content of the wood was determined in three replicates by drying the samples in an electric oven furnace. The average diameter of the logs was in the range from 70 to $100 \mathrm{~mm}$. The wood chip fractions were analyzed to assess the quality of chips. The fractionation process of chips was carried out on laboratory machine (wood chips screening machine). The sieve holes have the following dimensions: $\varnothing 32,16,6$ and $3 \mathrm{~mm}$. The samples wood chips with a weight of $1 \mathrm{~kg}$ from specific locations of the production of chips, i. e: after the cyclone, the screening machine and after the pneumatic conveying system were taken to testing. Then, the chips were poured into the screening machine and after $10 \mathrm{~min}$ of operation, the chips were weighed from each sieve. The weights of wood chips, was determined by a weighing scale with a precision of $1 \mathrm{~g}$. For each of the next sample of chips was performed three times the measurements. From the measurements was calculated the arithmetic mean. Multiple samples of chips were classified according to mill guidelines.

Matlab/Simulink to optimize the log cutting speed was used. Simulations to determine the variability of the clearance angle on the radius of the disc of chipper were also made.

\section{RESULTS AND DISCUSSION}

\section{The results of measurements of particle size distribution of wood chips}

The results of measurements of particle size distribution of wood chips for pulp mill are shown in Tab. 1.

Tab. 1: Particle size distribution of spruce wood chips taken after the cyclone, the screening machine and after the pneumatic conveying system for wood chips (for chipper's disc rotational speed of $370 \mathrm{rpm}$ and moisture content of the wood $-46.5 \%)$.

\begin{tabular}{|c|c|c|c|c|}
\hline \multirow[b]{2}{*}{$\begin{array}{l}\text { Dimensions of } \\
\text { the round holes } \\
\text { in the sieves } \\
(\mathrm{mm})\end{array}$} & \multicolumn{3}{|c|}{ Particle size distribution of spruce wood chips (average \%) } & \multirow[b]{2}{*}{ Notes } \\
\hline & $\begin{array}{c}\text { The fraction of } \\
\text { wood chips after } \\
\text { the cyclone }\end{array}$ & $\begin{array}{l}\text { The fraction of } \\
\text { wood chips after } \\
\text { the screening } \\
\text { machine }\end{array}$ & $\begin{array}{l}\text { The fraction of } \\
\text { wood chips after } \\
\text { the pneumatic } \\
\text { conveying system } \\
\text { for wood chips }\end{array}$ & \\
\hline 32 & 2.8 & 1.7 & 1.4 & Oversize fraction \\
\hline 16 & 45.9 & 42.5 & 38.9 & Accept fraction (desired) \\
\hline 6 & 46,0 & 52.9 & 57.0 & Undesirable fraction \\
\hline $\begin{array}{c}3 \\
0 \text { (pan) }\end{array}$ & $\begin{array}{c}3.4 \\
1.9 \\
\end{array}$ & $\begin{array}{l}1.9 \\
1.0\end{array}$ & $\begin{array}{l}2.2 \\
0.5\end{array}$ & $\begin{array}{l}\text { The fraction too small } \\
\text { (pins and fines) }\end{array}$ \\
\hline
\end{tabular}

The results show that the share of good chips in all measurement series was less than $46 \%$ relative to the total weight of the chips. The amount retained on each sieve is divided by the total weight of the sample to give a percentage. When wood chips pass through subsequent devices is observed to increase the amount undesirable fraction. The fractions a chip with a small nominal size (undesirable fraction) that have passed through a pneumatic conveying system exceed the value of 50\%. Such a high percentage of this fraction in the production of wood chips is unacceptable for the production of cellulose. One of the reasons for the large amount of undesirable fraction may be too high chipper knives speed. 


\section{Theoretical cutting velocity}

The process of chipping wood in a disc chipper is complex and includes phenomena related with cutting wood leading to the separation of chips, as well as pulling in wood through the cutting system (feed).

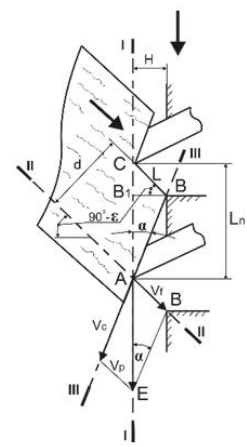

Fig. 1: The cutting log in disc chipper: $\alpha$-clearance angles (pull in angle), $\varepsilon-$ spout angle, $H$-knife height, $L-c h i p$ length, $L_{n}-$ distance between knives, $d$-log diameter, $v_{c}-$ cutting velocity, $v_{f}-$ feeding velocity, $v_{p}$-peripheral velocity.

Fig. 1 shows the process of wood chipping in a disc chipper with inclined wood feeding. The disc with knives rotates in the vertical plane I-I at the peripheral velocity $-v_{p}$. The wood feed occurs in the II-II plane, parallel to the direction of the fibers in the wood, at a velocity of $v_{f}$ Wood cutting occurs in the III-III plane. The cutting velocity $v_{c}$ can be determined by applying the sine formula (sine law) to the triangle ABE (Fig. 1).

Therefore:

$$
\frac{v_{f}}{\sin \alpha}=\frac{v_{p}}{\sin \left[\frac{\pi}{2}+\left(\left(\frac{\pi}{2}-\varepsilon\right)-\alpha\right)\right]}=\frac{v_{c}}{\sin \left[\frac{\pi}{2}-\left(\frac{\pi}{2}-\varepsilon\right)\right]}
$$

hence

$$
v_{c}=v_{p} \cdot \frac{\cos \left(\frac{\pi}{2}-\varepsilon\right)}{\cos \left[\left(\frac{\pi}{2}-\varepsilon\right)-\alpha\right]} \quad\left(\mathrm{m} \cdot \mathrm{s}^{-1}\right)
$$

for

$$
v_{p}=R_{c} \cdot \omega \quad\left(\mathrm{m} \cdot \mathrm{s}^{-1}\right)
$$

where: $\quad \omega$ - angular velocity of rotating $\operatorname{disc}\left(\operatorname{rad} \cdot \mathrm{s}^{-1}\right)$,

$R_{c}$ - cutting radius, ie. the distance between the axis of the disc and the considered the point of contact of contact of the cutting edge of the knife with wood log $(\mathrm{m})$, $\alpha$ - clearance angles (pull in angle) (o),

$\varepsilon$ - spout angle $\left({ }^{\circ}\right)$,

$v_{c}$ - cutting velocity $\left(\mathrm{m} \cdot \mathrm{s}^{-1}\right)$,

$v_{f}$ - feeding velocity $\left(\mathrm{m} \cdot \mathrm{s}^{-1}\right)$,

$v_{p}$ - peripheral velocity $\left(\mathrm{m} \cdot \mathrm{s}^{-1}\right)$.

\section{Actual cutting velocity distribution on the knife of chipper}

In order to determine the cutting velocity distribution, its values were calculated for the two extreme points of the knife. The maximum and minimum cutting radius was measured and the 
peripheral velocities were calculated for these points. In addition, the spout angle and clearance angles in the chipper were measured (Fig. 2). The rotational speed of the disc in the chipper is $370 \mathrm{rpm}$, so the angular velocity $-38.73 \mathrm{rad} \cdot \mathrm{s}^{-1}$. The measured chipper parameters are shown in Tab. 2.

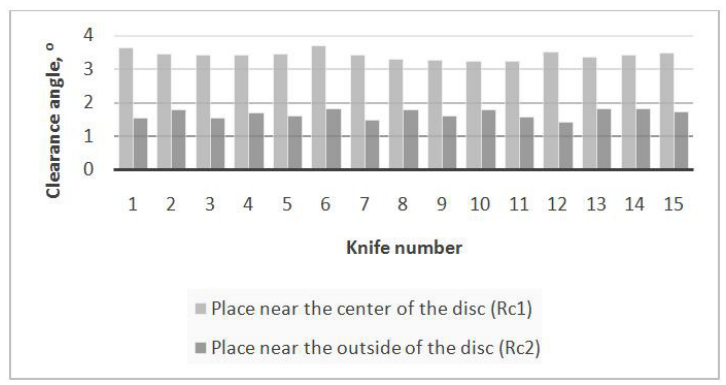

Fig. 2: Average values of measured clearance angles in the chipper.

According to the test results presented in Fig. 2, the average value for 15 knives for $R_{c 1}$ is $3^{\circ} 25^{\prime}(3,42)$, while for $R_{c 2}$ it is $1^{\circ} 40^{\prime}(1,67)$. The clearance angle is an important parameter of the knife positioning in the disc chipper which has major influence on the chips length (Reczulski 2018, Smith and Javid 1999). Different clearance angles lead to wood chips of different sizes. This case can also cause microcracks wood and consequently to the weakening and cracking of the formed chip.

Tab. 2: Characteristic parameters.

\begin{tabular}{|l|c|}
\hline \multicolumn{1}{|c|}{ Parameters } & Range \\
\hline Minimum cutting radius, $R_{c 1}$ & $0,32 \mathrm{~m}$ \\
\hline Maximum cutting radius, $R_{c 2}$ & $0,93 \mathrm{~m}$ \\
\hline Spout angle, $\varepsilon$ & $38^{\circ}$ \\
\hline Average clearance angles, $\alpha_{1}$ for $R_{c 1}$ & $3^{\circ} 25^{\prime}$ \\
\hline Average clearance angles, $\alpha_{2}$ for $R_{c 2}$ & $1^{\circ} 40^{\prime}$ \\
\hline
\end{tabular}

By substituting the cutting radius $R_{c 1}$ and $R_{c 2}$ in Eq. 3, peripheral velocities were calculated at both points, which are $v_{p 1}=12.39 \mathrm{~m} \cdot \mathrm{s}^{-1}$ and $v_{p 2}=36.02 \mathrm{~m} \cdot \mathrm{s}^{-1}$, respectively (Fig. 2 ). Then, cutting velocity $v_{c 1}=12.02 \mathrm{~m} \cdot \mathrm{s}^{-1}$ and $v_{c 2}=34.94 \mathrm{~m} \cdot \mathrm{s}^{-1}$ were determined from equation 2 . The $R_{c}$ is a value variable in time, and it depends on the diameter of $\log$ and its position in the spout.

\section{Determining the optimal distribution of cutting velocity vectors over the length of knives}

Knife velocity varies at any particular point in the spout opening due to the radial distance at that point. Multiple stem feeding produces different chipping environments for each log. The actual distribution of cutting velocity occurring on the chipper knife is shown in Fig. 3. 


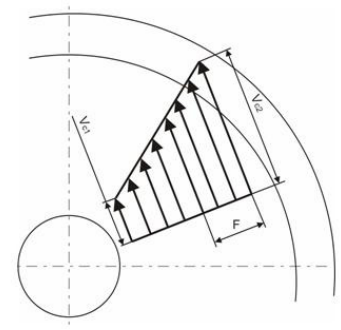

Fig. 3: Cutting velocity distribution on the chipper knife: $v_{c 1}, v_{c 2}$-cutting velocity, $F$ - too high cutting velocity.

Assuming that an increase in cutting speed above $25 \mathrm{~m} \cdot \mathrm{s}^{-1}$ (Hartler 1986, Reczulski 2015) has a significant impact on the production of pin chips, the chipper tested worked at the too high speed at the maximum cutting radius. Thus, the highest cutting velocity that occurs at the end of the knife (place near the outside of the disc) should not exceed $25 \mathrm{~m} \cdot \mathrm{s}^{-1}$. Angular velocity can be determined from the transformed equation 2 :

$$
\omega^{\prime}=\frac{v_{c} \cdot \cos \left(\left(\frac{\pi}{2}-\varepsilon\right)-\alpha^{\prime}\right)}{R_{c} \cdot \cos \left(\frac{\pi}{2}-\varepsilon\right)} \quad\left(\mathrm{rad} \cdot \mathrm{s}^{-1}\right)
$$

where: $\quad \omega^{\prime}$ - angular velocity of rotating disc (calculated) $\left(\mathrm{rad} \cdot \mathrm{s}^{-1}\right)$,

$\alpha^{\prime}$ - clearance angle (calculated) (o),

$v_{c}^{\prime}$ - cutting velocity (calculated) $\left(\mathrm{m} \cdot \mathrm{s}^{-1}\right)$.

To determine the optimal cutting velocities for logs, calculations of the angular velocity of the disc should be done for $v_{c 2}{ }^{\prime}=v_{c \max }=25 \mathrm{~m} \cdot \mathrm{s}^{-1}$ and $R_{c 2}$. In addition, the optimal clearance angles value $\alpha_{1}{ }^{\prime}, \alpha_{2}{ }^{\prime}$ for $R_{c 1}$ and $R_{c 2}$ respectively should be calculated from the relationship (Hartler 1996, Reczulski 2018):

$$
\alpha^{\prime}=\operatorname{arctg} \frac{L \cdot \sin \varepsilon}{2 \cdot R_{c} \cdot \sin \frac{\pi}{Z}}+\left(30^{\prime} \div 1^{0}\right)
$$

where: $\quad \alpha^{\prime}$ - clearance angle (calculated) $\left({ }^{\circ}\right)$,

$L=\mathrm{H} /$ sin $\varepsilon \cong 0.02 \mathrm{~m}-$ length of wood chips (m),

$\mathrm{H}$ - heights of each knives protruding from a disc surface (measurement carried out on the machine) (m),

$\mathrm{z}$ - number of knives in the disc chipper.

Model in Matlab/Simulink to calculate the parameters $\alpha^{\prime}$ and $v_{c}^{\prime}$ was used (Fig. 4). The cutting radius $\left(R_{c}=320-930 \mathrm{~mm}\right)$, spout angle, $\left(\varepsilon=38^{\circ}\right)$, length of wood chips $(L=20 \mathrm{~mm})$, number of knives in the disc chipper $(\mathrm{z}=15)$, cutting speed of the disc $v_{\text {cmax }}=25 \mathrm{~m} \cdot \mathrm{s}^{-1}$ and calculated parameters $-\alpha^{\prime}, \omega_{2}^{\prime}$, are use as input parameters in Matlab/Simulink model. 

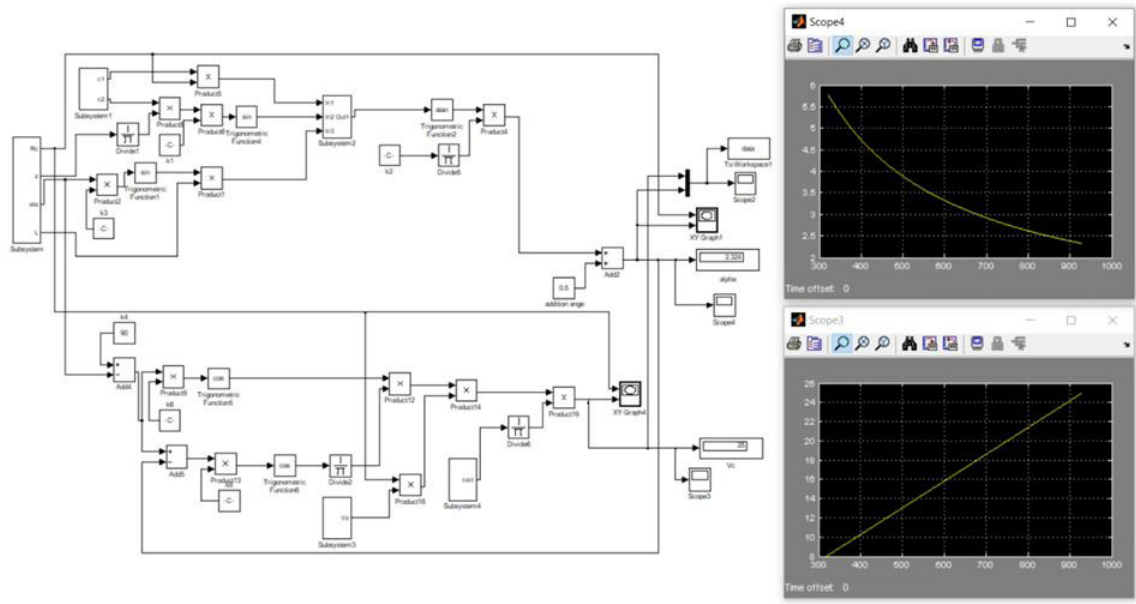

Fig. 4: Panel subsystem block diagram.

According to Equation 5, the clearance angle $\alpha_{1}^{\prime}$, for $R_{c 1}$ should be $5^{\circ} 47^{\prime}\left(5.79^{\circ}\right)$ and the angle $\alpha_{2}$, for $R c_{2}-2^{\circ} 19^{\prime}\left(2.32^{\circ}\right)$. The graph of the clearance (pull-in) angle change along the cutting radius was calculated from equation 5 and shown in the Fig. 5 . These are the optimal clearance angles to achieve a $20 \mathrm{~mm}$ chip length along the cutting radius.

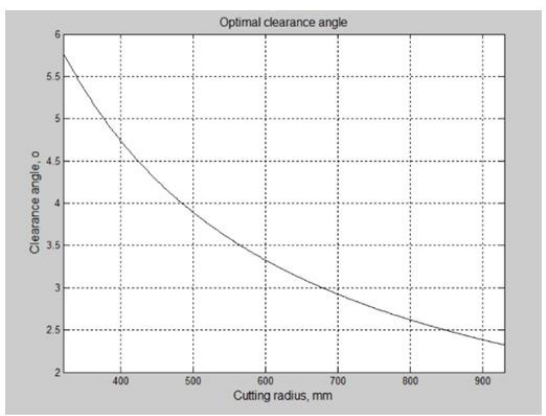

Fig. 5: Optimal clearance angles.

Meanwhile, the measurements showed that the average values of the clearance angles were $3^{\circ} 25^{\prime}$ and $1^{\circ} 40^{\prime}$. Thus the parameters of the cutting system used in the disc chipper are incorrect and favor the production of wood chips with shorter lengths than assumed.

Fig. 6 presents two curves illustrating the course of variability of the clearance angles $\alpha$ i $\alpha^{\prime}$ calculated using the Matlab/Simulink model. In order to obtain the possible course of variability of the actual clearance angle $(\alpha)$ along the cutting radius, a computer simulation was also carried out. Two points are placed on the graph. These are the only clearance angles measured in the area of each knife in the chipper. According to the $\alpha$-graph, the length of the chips will be approx. $10 \mathrm{~mm}$. Thus, the chipper works with the incorrect clearance angles, increasing the excessive amount of fines and pin fractions during chipping wood. 


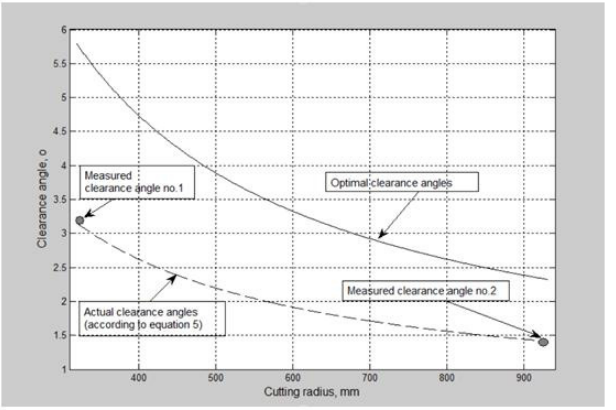

Fig. 6: Comparison of simulation results for the clearance angles $-\alpha i \alpha$.

Then the maximum angular velocity $\omega_{2}^{\prime}$ in point 2 for $v_{c 2}{ }^{\prime}=v_{c \max }=25 \mathrm{~m} \cdot \mathrm{s}^{-1}$ will be $28.25 \mathrm{rad} \cdot \mathrm{s}^{-1}$ (Eq. 4), i.e. $270 \mathrm{rpm}$. According to equation 2, cutting speed $v_{c 1}$ ' was calculated at point 1 . For $\alpha_{1}^{\prime}$ and $v_{p 1}{ }^{\prime}=9.04 \mathrm{~m} \cdot \mathrm{s}^{-1}(\mathrm{Eq} .3)$, the cutting velocity was $v_{c 1}{ }^{\prime}=8.04 \mathrm{~m} \cdot \mathrm{s}^{-1}$. According to calculations, the cutting velocity vectors at a chipper disc rotational speed of $270 \mathrm{rpm}$ would change within the acceptable limits from 8.0 to $25.0 \mathrm{~m} \cdot \mathrm{s}^{-1}$ (Fig. 7).

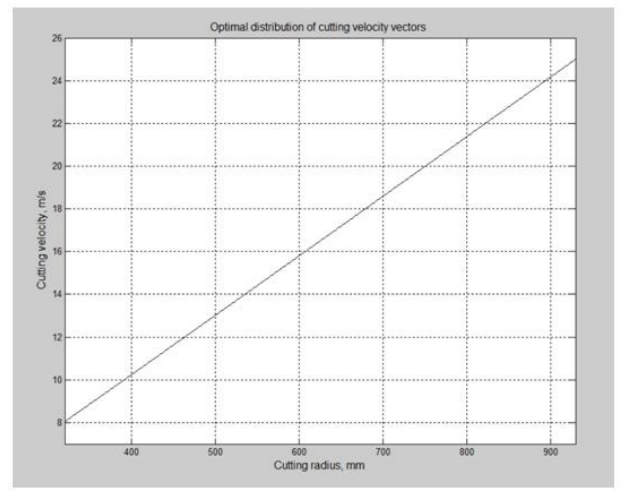

Fig. 7: Optimal distribution of cutting velocity vectors over the length of knives.

The wood chipping test at a knife speed of $25 \mathrm{~m} \cdot \mathrm{s}^{-1}$ was carried out. The results of measurements of particle size distribution of wood chips are shown in Tab. 3 . The tests were carried out without changing the clearance angles in the chipper. 
Tab. 3: Particle size distribution of spruce wood chips taken after the cyclone, the screening machine and after the pneumatic conveying system for wood chips (for chipper's disc rotational speed of $270 \mathrm{rpm}$ and moisture content of the wood - 46.5\%).

\begin{tabular}{|c|c|c|c|c|}
\hline \multirow{2}{*}{$\begin{array}{c}\text { Dimensions of the } \\
\text { round holes in the } \\
\text { sieves (mm) }\end{array}$} & $\begin{array}{c}\text { Particle size distribution of spruce wood chips (\%) (average) } \\
\text { The fraction of } \\
\text { wood chips after } \\
\text { the cyclone }\end{array}$ & $\begin{array}{c}\text { The fraction of } \\
\text { wood chips after } \\
\text { the screening } \\
\text { machine }\end{array}$ & $\begin{array}{c}\text { The fraction of } \\
\text { wood chips after the } \\
\text { pneumatic conveying } \\
\text { system for wood chips }\end{array}$ & \multirow{2}{*}{ Notes } \\
\hline 32 & $3.1(0.3)$ & $1.9(0.2)$ & $1.5(0.1)$ & Oversize fraction \\
\hline 16 & $47.2(1.3)$ & $43,9(1.4)$ & $39.8(0.9)$ & $\begin{array}{c}\text { Accept fraction } \\
\text { (desired) }\end{array}$ \\
\hline 6 & $44,9(-1.1)$ & $51.7(-1.2)$ & $56.2(-0.8)$ & $\begin{array}{c}\text { Undesirable } \\
\text { fraction }\end{array}$ \\
\hline 30 & $3.1(-0.3)$ & $1.6(-0.3)$ & $2.1(-0.1)$ & $\begin{array}{c}\text { The fraction too } \\
\text { small } \\
\text { (pan) }\end{array}$ \\
$1.7(-0.2)$ & $0.9(-0.1)$ & $0.4(-0.1)$ & \\
\hline
\end{tabular}

( ) - the difference in particle size distribution of spruce wood chips (\%) (average)

Comparison of test results carried out at different rotational speed of the disc in the chipper is shown in Figs. 8, 9 and 10.

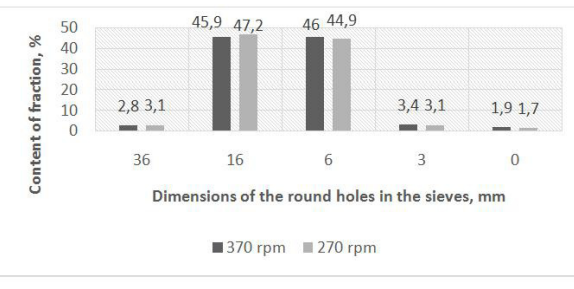

Fig. 8: The fraction of wood chips after the cyclone.

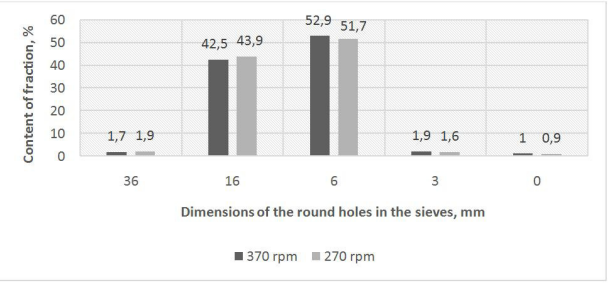

Fig. 9: The fraction of wood chips after the screening machine.

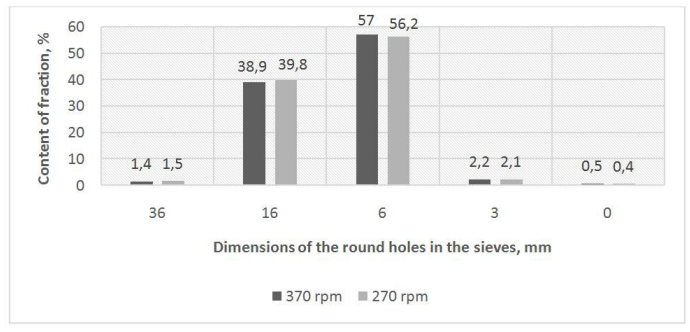

Fig. 10: The fraction of wood chips after the pneumatic conveying system for wood chips.

Reducing knife speed reduced the amount of too small chips produced for dimensions of round holes in the sieves $-6 \mathrm{~mm}$ and $3 \mathrm{~mm}$. Similar findings from the study were noted by Hartler (1986), Edelman and Stuart (1992), Hernandez and Boulanger 1997 and Abdallah et al. (2011). Reducing the chipper's disc rotational speed to $270 \mathrm{rpm}$, the generation of fine particles 
(pines and fines) fluctuated only $0.3 \%$, indicating a minimal effect of the knife velocity on too small fraction generation (round holes $-3 \mathrm{~mm}$ ) (Smith and Javid 1999). However, the amount of acceptable and oversized wood chips fraction increased. The accept fraction increased by $1.3 \%$ after the cyclone. This is a small increase after reducing the disc speed of $100 \mathrm{rpm}$. Reducing the rotational speed of the chipper shaft reduced the speed of chips ejection, which reduced their crushing and cracking in the chipper and cyclone discharge pipe.

It should also be taken into account that reducing the rotational speed of the chipper would cause a decrease in the kinetic energy of the rotating masses and significantly reduce chipper performance.

The test results also show that the variation in the amount of oversize fraction chips fluctuated around $0.3 \%$. It should also be noted that the presence of knot wood, too small log diameters or the log growth pattern may have affected the test results. The results also showed a decrease in the amount of acceptable fraction measured after the pneumatic system compared to the fraction after the cyclone by about $0.4 \%$. This is probably caused by wrong conditions the transport of wood chips or the production of a significant amount of wood chips with microcracks leading to their cracking (Reczulski 2015).

\section{CONCLUSIONS}

For economic reasons, it is preferable to use higher rotational speeds in the chipper, which ensure better use kinetic energy of the rotating mass. At the same time, however, increasing the rotational speed of the chipper shaft increases the speed of the chips, which significantly intensifies their crushing and cracking in the chipper and the cyclone discharge pipe. In addition, as the wood cutting speed increases in wood chippers, the amount of too small fraction (pins and fines) in the wood chips produced also increases. This has a significant impact on pulp properties, pulp production, and pulp quality, particularly in the kraft pulping. In addition to the rotational speed of the chipper shaft, the design and operation of the chipper cutting system affects the wood chipping process.

An important design parameter that has a decisive impact on the feeding velocity of wood in the cutting process is the clearance angle. Achieving the same feeding velocity of log over the entire length of the knife is a necessary condition for cutting off chips of similar length. The test results confirmed that parameters of the cutting system used in the disc chipper are incorrect and favor the production of wood chips with shorter lengths than assumed.

To sum up, the main chipper performance challenge is to find an optimum of knives speed to produce the preferred compromise between pin chip generation and overthick generation.

\section{REFERENCES}

1. Abdallah, R., Auchet, S., Méausoone, P. J., 2011: Experimental study about the effects of disc chipper settings on the distribution of wood chip size. Biomass and Bioenergy 35(2): 843-852.

2. Ebrahim, E.,Z., Ghazy, M., 2016: Influence of drum chipper setting on the wood chips performance. Misr Journal of Agricultural Engineering 33(4): 1293-1312

3. Edelman, J.,S., Stuart, W.,B., 1992: The effect of disc speed on sawmill residue wood chip quality Text. Tappi Pulping Conference Proceedings, Pp 375-380. 
4. Goncalves, R., Neri, A., C., 2005: Orthogonal cutting forces in juvenile and mature Pinus taeda wood. Scientia Agricola 62(4): 310-318.

5. Güntekin, E., Aydin, Y., T., Niemz, P., 2016: Some orthotropic elastic properties of Fagus orientalis as influenced by moisture content. Wood Research 61(1): 95-104.

6. Hartler, N., 1986: Chipper design and operation for optimum chip quality. Tappi Journal 69(10): 62-66.

7. Hartler, N., 1996: Achievement and significance of optimal chip quality. Tappi Journal 79(2): 259-264.

8. Hartler, N., Stade, Y., 1997: Chipper operation for improved chip quality. Svensk Papperstid 80(14): 477.

9. Hellström, L., Gradin, P., Carlberg, T., 2008: A method for experimental investigation of the wood chipping process. Nordic Pulp \& Paper Research Journal 23(3): 339-342.

10. Hellström, L.M., Isaksson, P., Gradin, P.A., Eriksson, K., 2009: An analytical and numerical study of some aspects of the wood chipping process. Nordic Pulp and Paper Research Journal 24(2): 225-230.

11. Hernandez, R., Boulanger, J., 1997: Effect of the rotation speed on the size distribution of black spruce pulp chips produced by chipper-canter. Forest Product Journal 47(4): 43-49.

12. Hernandez, R., Lessard, J., 1997: Effect of cutting width and cutting height on the size distribution of black spruce pulp chips produced by a chipper-canter. Forest Product Journal 47(3): 89-95.

13. Hernandez, R., Passarini, L., Koubaa, A., 2014: Effect of temperature and moisture content on selected wood mechanical properties involved in the chipping process. Forest Product Journal 48(6): 1281-1301.

14. Koman, S., Feher, S., 2015: Basic density of hardwoods depending on age and site. Wood Research 60(6): 907-912.

15. Law, K. N., Lanouette, R., 2000: Effect of mechanical conditioning of chips on the quality of softwood TMP. Pulp and Paper Canada 101(7): T189-T193.

16. Papworth, R.L., Erickson, J.R., 1966: Power requirements for producing wood chips. Forest Products Journal 16(10): 31-36.

17. Petráš, R., Mecko, J.,Krupová, D., Slamka, M., Pažitný, A., 2019: Aboveground biomass basic density of softwoods tree species. Wood Research 64(2): 205-212.

18. Reczulski, M., 2015: Analysis of the construction and operation of system wood chipping and transfer chips. Wood Research 60(4): 671-678.

19. Reczulski, M., 2016: The system wood chipping in disc chipper - problems of uniformity of chips length. Wood Research 61(3): 433-442.

20. Reczulski, M., 2018: Optimization of the clearance angle in industrial disc chipper. Wood Research 63(2): 295-303.

21. Röser, D., Mola-Yudego, B., Prinz, R., Emer, B., Sikanen,L., 2012: Chipping operations and efficiency in different operational environments. Silva Fennica 46(2): 275-286.

22. Schönfelder, O., Zeidler, A., Borůvka, V., Bílek, L., 2019: Impact of silvicultural measures on the quality of Scots pine wood Part II. Effect of site. Wood Research 64(5): 789-798.

23. Smith, D., Javid S., R., 1999: Improved chipper design yields better chips for chemical pulping. Pulp and Paper 73(7): 54-56.

24. Twaddle, A.A., 1990: Survey of disc chippers in the Southeastern USA and their effects on chip quality text. (ed. A.A. Twaddle, W.F. Watson). 1990 Tappi Pulping Conference Proceedings, Pp 77-86. 
25. Twaddle, A., 1997: The influence of species, chip length, and ring orientation on chip thickness. Tappi Journal 80(6): 123-131.

26. Uhmeier, A., 1995: Some fundamental aspects of wood chipping. Tappi Journal 78(10): 79-86.

\author{
Mariusz Reczulski* \\ Lodz University of Technology \\ Centre of Papermaking and Printing \\ 223 Wólczańska St. \\ 90-924 LoDZ \\ Poland \\ *Corresponding author: mariusz.reczulski@p.lodz.pl
}

